\title{
Best Proximity Point Results in Complex Valued Metric Spaces
}

\author{
Binayak S. Choudhury, ${ }^{1}$ Nikhilesh Metiya, ${ }^{2}$ and Pranati Maity ${ }^{1}$ \\ ${ }^{1}$ Department of Mathematics, Bengal Engineering and Science University, Shibpur, Howrah, West Bengal 711103, India \\ ${ }^{2}$ Department of Mathematics, Bengal Institute of Technology (TIG), 1 Government Colony, Kolkata, West Bengal 700150, India
}

Correspondence should be addressed to Pranati Maity; pranati.math@gmail.com

Received 20 January 2014; Accepted 13 August 2014; Published 27 August 2014

Academic Editor: Ying Hu

Copyright (c) 2014 Binayak S. Choudhury et al. This is an open access article distributed under the Creative Commons Attribution License, which permits unrestricted use, distribution, and reproduction in any medium, provided the original work is properly cited.

\begin{abstract}
We introduce the concept of proximity points for nonself-mappings between two subsets of a complex valued metric space which is a recently introduced extension of metric spaces obtained by allowing the metric function to assume values from the field of complex numbers. We apply this concept to obtain the minimum distance between two subsets of the complex valued metric spaces. We treat the problem as that of finding the global optimal solution of a fixed point equation although the exact solution does not in general exist. We also define and use the concept of P-property in such spaces. Our results are illustrated with examples.
\end{abstract}

\section{Introduction and Preliminaries}

In this paper we prove certain proximity point results to obtain the minimum distance between two subsets of a complex valued metric space. Essentially it is a global optimization problem which we treat here as the problem of finding the global optimal solution of a fixed point iteration. It is a part of the more general category of problems of finding minimum distances between two objects. In geometry it has led to the concept of geodesics, a curve along which the optimal distance between two given points of the space is realized [1]. Examples abound in physical theories, especially in the general theory of relativity, where finding the physically possible shortest path is sometimes the main task [2].

In proximity point problems our objects are sets. Here our aim is to find the distance between two sets $A$ and $B$ with the help of a function $f$ defined from $A$ to $B$. Precisely we want to find a solution to the problem of minimizing the distance between $x$ and $f x$ where $x$ is varied over the set $A$. Equivalently we want to find the optimal solution of the equation $x=f x$ although the exact solution does not in general exist as in the case where $A$ and $B$ are disjoint. It is at this point the best approximation theorems and the best proximity point theorems have their roles to play. The best approximation theorems provide the best approximate solutions which need not be globally optimal. For instance, let us consider the following Ky Fan's best approximation theorem.

Theorem 1 (see [3]). Let A be a nonempty compact convex subset of a normed linear space $X$ and let $T: A \rightarrow X$ be a continuous function. Then there exists $x \in A$ such that $\|x-T x\|=d(T x, A)=\inf \{\|T x-a\|: a \in A\}$.

The element $x$ in the above theorem need not give the optimum value of $\|x-T x\|$.

Proximity point result was first proved by [4]. After that several results on proximity have followed. Particularly, in the general setting of metric spaces there are a good number of results, and [5-14] are instances of these results. As we have already stated in this paper we introduce the concept of proximity points in complex valued metric spaces.

First we describe the complex valued metric spaces.

It is a generalization of metric space introduced by Azam et al. [15] where the metric function assumes values from the field of complex numbers. Following this work several works on complex valued metric spaces, especially on fixed point and related topics, have been done, some of which are noted in [16-18]. It opens the scope of incorporating concepts from complex analysis in the domain of metric spaces. In fact, there are large efforts for generalizing metric spaces by changing the form and interpretation of the metric function. 
Gähler [19] introduced 2-metric spaces where a real number is assigned to any three points of the space. Probabilistic metric spaces were introduced by Schweizer and Sklar [20, 21] in which any pair of points is assigned to a suitable distribution function making possible a probabilistic sense of distance. Fuzzy metric spaces were introduced in more than one way by various means of fuzzification as, for example, in [22] by assigning any pair of points to a suitable fuzzy set and spelling out the triangular inequality by using a t-norm. Another example is in the work of Kaleva and Seikkala [23] where any pair of points is assigned to a fuzzy number. Gmetric space [24] is another generalization in which every triplet of points is assigned to a nonnegative real number but in a different way than in 2-metric spaces. There are also other extensions of the metric which are not mentioned above. It can be seen that in recent times efforts of extending the concept of metric space have continued in a rapid manner.

Below we describe the essential features of complex valued metric spaces which we require here.

Let $\mathscr{C}$ be the set of complex numbers and $z_{1}, z_{2} \in \mathscr{C}$. Define a partial order $\precsim$ on $\mathscr{C}$ as follows:

$$
z_{1} \precsim z_{2} \text { iff } \operatorname{Re}\left(z_{1}\right) \leq \operatorname{Re}\left(z_{2}\right), \operatorname{Im}\left(z_{1}\right) \leq \operatorname{Im}\left(z_{2}\right) \text {. }
$$

It follows that $z_{1} \lesssim z_{2}$ if one of the following conditions is satisfied:

(i) $\operatorname{Re}\left(z_{1}\right)=\operatorname{Re}\left(z_{2}\right), \operatorname{Im}\left(z_{1}\right)<\operatorname{Im}\left(z_{2}\right)$;

(ii) $\operatorname{Re}\left(z_{1}\right)<\operatorname{Re}\left(z_{2}\right), \operatorname{Im}\left(z_{1}\right)=\operatorname{Im}\left(z_{2}\right)$;

(iii) $\operatorname{Re}\left(z_{1}\right)<\operatorname{Re}\left(z_{2}\right), \operatorname{Im}\left(z_{1}\right)<\operatorname{Im}\left(z_{2}\right)$;

(iv) $\operatorname{Re}\left(z_{1}\right)=\operatorname{Re}\left(z_{2}\right), \operatorname{Im}\left(z_{1}\right)=\operatorname{Im}\left(z_{2}\right)$.

In particular, we will write $z_{1} \preccurlyeq z_{2}$ if $z_{1} \neq z_{2}$ and one of (i), (ii), and (iii) is satisfied and we will write $z_{1} \prec z_{2}$ if only (iii) is satisfied.

Note that

$$
z_{1} \precsim z_{2}, \quad z_{2} \prec z_{3} \Longrightarrow z_{1} \prec z_{3} \text {. }
$$

Definition 2. Let $A$ be a subset of $\mathscr{C}$. If there exists $u \in \mathscr{C}$ such that $z \preceq u$, for all $z \in A$, then $A$ is bounded above and $u$ is an upper bound. Similarly, if there exists $l \in \mathscr{C}$ such that $l \precsim z$, for all $z \in A$, then $A$ is bounded below and $l$ is a lower bound.

Definition 3. For a subset $A \subseteq \mathscr{C}$ which is bounded above if there exists an upper bound $s$ of $A$ such that, for every upper bound $u$ of $A, s \preceq u$, then the upper bound $s$ is called the least upper bound (lub) of $A$ or sup $A$. Similarly, for a subset $A \subseteq \mathscr{C}$ which is bounded below if there exists a lower bound $t$ of $A$ such that, for every lower bound $l$ of $A, l \preceq t$, then the lower bound $t$ is called the greatest lower bound (glb) of $A$ or $\inf A$.

Suppose that $A \subseteq \mathscr{C}$ is bounded above. Then there exists $q=u+i v \in \mathscr{C}$ such that $z=x+i y \preceq q=u+i v$, for all $z \in A$. It follows that $x \lesssim u$ and $y \precsim v$, for all $z=x+i y \in A$; that is, $S=\{x: z=x+i y \in A\}$ and $T=\{y: z=x+i y \in A\}$ are two sets of real numbers which are bounded above. Hence both $\sup S$ and $\sup T$ exist. Let $x^{*}=\sup S$ and $y^{*}=\sup T$. Then clearly, $z^{*}=x^{*}+i y^{*}$ is the least upper bound (lub) of $A$ or $\sup A$.

Similarly, if $A \subseteq \mathscr{C}$ is bounded below, then $z^{* *}=x^{* *}+$ $i y^{* *}$ is the greatest lower bound (glb) of $A$ or inf $A$, where $x^{* *}=\inf S=\{x: z=x+i y \in A\}$ and $y^{* *}=\inf T=\{y: z=$ $x+i y \in A\}$.

Any subset $A \subseteq \mathscr{C}$ which is bounded above has the least upper bound (lub) or supremum. Equivalently, any subset $A \subseteq \mathscr{C}$ which is bounded below has the greatest lower bound (glb) or infimum.

Definition 4 (see [15]). Let $X$ be a nonempty set. Suppose that the mapping $d: X \times X \rightarrow \mathscr{C}$ satisfies

(i) $0 \precsim d(x, y)$, for all $x, y \in X, d(x, y)=0$ if and only if $x=y$;

(ii) $d(x, y)=d(y, x)$, for all $x, y \in X$;

(iii) $d(x, y) \lesssim d(x, z)+d(z, y)$, for all $x, y, z \in X$.

Then $d$ is called a complex valued metric on $X$ and $(X, d)$ is called a complex valued metric space.

Definition 5. Let $(X, d)$ be a complex valued metric space and $\left\{x_{n}\right\}$ a sequence in $X$ and $x \in X$.

(i) If for every $c \in \mathscr{C}$ with $0 \prec c$ there is $n_{0} \in \mathbf{N}$ such that, for all $n>n_{0}, d\left(x_{n}, x\right) \prec c$, then $\left\{x_{n}\right\}$ is said to be convergent, $\left\{x_{n}\right\}$ converges to $x$, and $x$ is the limit point of $\left\{x_{n}\right\}$. We denote this by $\lim _{n \rightarrow \infty} x_{n}=x$ or $x_{n} \rightarrow x$ as $n \rightarrow \infty$.

(ii) If for every $c \in \mathscr{C}$ with $0 \prec c$ there is $n_{0} \in \mathbf{N}$ such that, for all $n, m>n_{0}, d\left(x_{n}, x_{m}\right) \prec c$, then $\left\{x_{n}\right\}$ is said to be a Cauchy sequence.

(iii) If every Cauchy sequence in $X$ is convergent, then $(X, d)$ is a complete complex valued metric space.

Definition 6. Let $(X, d)$ be a complex valued metric space and $A \subseteq X$. The set $A$ is said to be bounded if there exists $r \in \mathscr{P}=$ $\{u+i v: u \geq 0, v \geq 0\}$ such that $d(x, y) \precsim r$, for all $x, y \in A$.

Clearly, for any bounded subset $A \subseteq X$, the set $\{d(x, y)$ : $x, y \in A\} \subseteq \mathscr{C}$ is both bounded below and above and hence sup $\{d(x, y): x, y \in A\}$ and inf $\{d(x, y): x, y \in A\}$ exist.

Lemma 7 (see [15]). Let $(X, d)$ be a complex valued metric space and $\left\{x_{n}\right\}$ a sequence in $X$. Then $\left\{x_{n}\right\}$ converges to $x$ if and only if $d\left(x_{n}, x\right) \rightarrow 0$ as $n \rightarrow \infty$.

Note 1. We can also replace the limit in Lemma 7 by the equivalent limiting condition $\left|d\left(x_{n}, x\right)\right| \rightarrow 0$ as $n \rightarrow \infty$.

Lemma 8. Let $(X, d)$ be a complex valued metric space and $\left\{x_{n}\right\}$ a sequence in $X$. Then $\left\{x_{n}\right\}$ is a Cauchy sequence if and only if $d\left(x_{n}, x_{m}\right) \rightarrow 0$ as $n, m \rightarrow \infty$.

Note 2. We can also replace the limit in Lemma 8 by the equivalent limiting condition $\left|d\left(x_{n}, x_{m}\right)\right| \rightarrow 0$ as $n \rightarrow \infty$. 
Definition 9. Let $(X, d)$ be a complex valued metric space, $T$ : $X \rightarrow X$ and $x \in X$. Then the function $T$ is continuous at $x$ if for any sequence $\left\{x_{n}\right\}$ in $X$,

$$
x_{n} \longrightarrow x \Longrightarrow T x_{n} \longrightarrow T x
$$

Definition 10. Let $(X, d)$ be a complex valued metric space. A set $A \subseteq X$ is called closed if for any sequence $\left\{x_{n}\right\}$ in $A$, $x_{n} \rightarrow x$ implies $x \in A$.

Next we define the proximity point and some related concepts in complex valued metric space.

Let $A$ and $B$ be two nonempty bounded subsets of a complex valued metric space $(X, d)$. Then $\{d(x, y): x \in$ $A, y \in B\} \subseteq \mathscr{C}$ is always bounded below by $z_{0}=0+i 0$ and hence $\inf \{d(x, y): x \in A, y \in B\}$ exists. Here we define

$$
\begin{gathered}
\operatorname{dist}(A, B)=\inf \{d(x, y): x \in A, y \in B\}, \\
A_{0}=\{x \in A: d(x, y)=\operatorname{dist}(A, B) \text { for some } y \in B\}, \\
B_{0}=\{y \in B: d(x, y)=\operatorname{dist}(A, B) \text { for some } x \in A\} .
\end{gathered}
$$

From the above definition, it is clear that for every $x \in A_{0}$ there exists $y \in B_{0}$ such that $d(x, y)=\operatorname{dist}(A, B)$ and conversely, for every $y \in B_{0}$ there exists $x \in A_{0}$ such that $d(x, y)=\operatorname{dist}(A, B)$.

Definition 11. Let $A$ and $B$ be two nonempty bounded subsets of a complex valued metric space $(X, d)$ and $T: A \rightarrow B$ a non-self-mapping. A point $x \in A$ is called a best proximity point of $T$ if $d(x, T x)=\operatorname{dist}(A, B)$.

The definition of $P$-property and weak $P$-property was introduced in [13] and [14], respectively.

Now we define them in complex valued metric space.

Definition 12. Let $A$ and $B$ be two nonempty subsets of a metric space $(X, d)$ with $A_{0} \neq \emptyset$. Then the pair $(A, B)$ is said to have the $P$-property if, for any $x_{1}, x_{2} \in A_{0}$ and $y_{1}, y_{2} \in B_{0}$,

$$
\left.\begin{array}{l}
d\left(x_{1}, y_{1}\right)=\operatorname{dist}(A, B) \\
d\left(x_{2}, y_{2}\right)=\operatorname{dist}(A, B)
\end{array}\right\} \Longrightarrow d\left(x_{1}, x_{2}\right)=d\left(y_{1}, y_{2}\right)
$$

Definition 13. Let $(A, B)$ be a pair of nonempty subsets of a complex valued metric space $(X, d)$ with $A_{0} \neq \emptyset$. Then the pair $(A, B)$ is said to have the weak $P$-property if and only if

$$
\left.\begin{array}{l}
d\left(x_{1}, y_{1}\right)=\operatorname{dist}(A, B) \\
d\left(x_{2}, y_{2}\right)=\operatorname{dist}(A, B)
\end{array}\right\} \Longrightarrow d\left(x_{1}, x_{2}\right) \precsim d\left(y_{1}, y_{2}\right)
$$

where $x_{1}, x_{2} \in A_{0}$ and $y_{1}, y_{2} \in B_{0}$.

Example 14. Let us consider the complex valued metric space $(X, d)$ where $X=C$ and let $d: X \times X \rightarrow \mathscr{C}$ be given as

$$
d\left(z_{1}, z_{2}\right)=\left|x_{1}-x_{2}\right|+i\left|y_{1}-y_{2}\right|
$$

where $z_{1}=x_{1}+i y_{1}, \quad z_{2}=x_{2}+i y_{2}$.
Let $A$ and $B$ be two subsets of $X$ given by

$$
\begin{aligned}
A= & \{z \in C: \operatorname{Re}(z)=-1,0 \leq \operatorname{Im}(z) \leq 1\} \\
& \cup\{z \in C: \operatorname{Re}(z)=1,0 \leq \operatorname{Im}(z) \leq 1\}, \\
B= & \left\{z \in C: \operatorname{Re}(z)=-2^{n}, 0 \leq \operatorname{Im}(z) \leq 1\right\} \\
& \cup\left\{z \in C: \operatorname{Re}(z)=2^{n}, 0 \leq \operatorname{Im}(z) \leq 1\right\},
\end{aligned}
$$

where $n$ is a fixed positive integer.

Notice that

$$
\operatorname{dist}(A, B)=2^{n}-1, \quad A_{0}=A, \quad B_{0}=B \text {. }
$$

It can be verified that for $x_{1}, x_{2} \in A_{0}$ and $y_{1}, y_{2} \in B_{0}$

$$
\left.\begin{array}{l}
d\left(x_{1}, y_{1}\right)=\operatorname{dist}(A, B) \\
d\left(x_{2}, y_{2}\right)=\operatorname{dist}(A, B)
\end{array}\right\} \Longrightarrow d\left(x_{1}, x_{2}\right) \precsim d\left(y_{1}, y_{2}\right) ;
$$

that is, the pair $(A, B)$ satisfies the weak $P$-property.

Particularly, let $x_{1}=-1, x_{2}=1 \in A_{0}$ and $y_{1}=-2^{n}$, $y_{2}=2^{n} \in B_{0}$. Then,

$$
\begin{aligned}
& \left.\begin{array}{l}
d\left(x_{1}, y_{1}\right)=\operatorname{dist}(A, B) \\
d\left(x_{2}, y_{2}\right)=\operatorname{dist}(A, B)
\end{array}\right\} \text { but } 2=d\left(x_{1}, x_{2}\right) \\
& \neq d\left(y_{1}, y_{2}\right)=2^{n+1} \text {. }
\end{aligned}
$$

So, the pair $(A, B)$ does not satisfy the $P$-property.

Remark 15. Let $(A, B)$ be a pair of nonempty subsets of a complex valued metric space $(X, d)$ with $A_{0} \neq \emptyset$. If the pair $(A, B)$ satisfies the $P$-property then it also satisfies the weak $P$-property. But the converse is not true.

\section{Main Results}

Theorem 16. Let $(A, B)$ be a pair of nonempty closed and bounded subsets of a complete complex valued metric space $(X, d)$ such that $A_{0}$ is nonempty and the pair $(A, B)$ satisfies the weak P-property. Let $T: A \rightarrow B$ be a mapping with $T\left(A_{0}\right) \subseteq B_{0}$. If there exists a real number $k$ with $0<k<1$ such that, for all $x, y \in A$,

$$
d(T x, T y) \precsim k M(x, y),
$$

where

$$
\begin{aligned}
M(x, y)=( & \{d(y, T x)-\operatorname{dist}(A, B)\} \\
& \cdot\{d(x, T y)-\operatorname{dist}(A, B)\} \\
& \cdot\{d(x, T x)-\operatorname{dist}(A, B)\} \\
& \cdot\{d(y, T y)-\operatorname{dist}(A, B)\}) \\
\times & (1+d(x, y))^{-1}+d(x, y),
\end{aligned}
$$

then $T$ has a unique best proximity point in $A$. 
Proof. Let $x_{0} \in A_{0}$. Since $T x_{0} \in T\left(A_{0}\right) \subseteq B_{0}$, there exists $x_{1} \in A_{0}$ such that $d\left(x_{1}, T x_{0}\right)=\operatorname{dist}(A, B)$. Again, since $T x_{1} \in$ $T\left(A_{0}\right) \subseteq B_{0}$, there exists $x_{2} \in A_{0}$ such that $d\left(x_{2}, T x_{1}\right)=$ $\operatorname{dist}(A, B)$. Continuing the process, we construct a sequence $\left\{x_{n}\right\}$ in $A_{0}$ such that

$$
d\left(x_{n+1}, T x_{n}\right)=\operatorname{dist}(A, B), \quad \forall n \in N .
$$

Since the pair $(A, B)$ satisfies the weak $P$-property, we conclude that

$$
d\left(x_{n}, x_{n+1}\right) \precsim d\left(T x_{n-1}, T x_{n}\right), \quad \forall n \in N .
$$

If $x_{n}=x_{n+1}$, then it follows from (14) that $x_{n} \in A_{0} \subseteq A$ is a best proximity point of $T$. So we assume $x_{n} \neq x_{n+1}$ for all $n \in N$; that is, $d\left(x_{n}, x_{n+1}\right) \neq 0$ for all $n \in N$. Applying (12) in (15), we have

$$
d\left(x_{n}, x_{n+1}\right) \precsim d\left(T x_{n-1}, T x_{n}\right) \precsim k M\left(x_{n-1}, x_{n}\right),
$$

where

$$
\begin{aligned}
M\left(x_{n-1}, x_{n}\right)=( & \left\{d\left(x_{n}, T x_{n-1}\right)-\operatorname{dist}(A, B)\right\} \\
& \cdot\left\{d\left(x_{n-1}, T x_{n}\right)-\operatorname{dist}(A, B)\right\} \\
& \cdot\left\{d\left(x_{n-1}, T x_{n-1}\right)-\operatorname{dist}(A, B)\right\} \\
& \left.\cdot\left\{d\left(x_{n}, T x_{n}\right)-\operatorname{dist}(A, B)\right\}\right) \\
\times & \left(1+d\left(x_{n-1}, x_{n}\right)\right)^{-1}+d\left(x_{n-1}, x_{n}\right) \\
= & \left(0 \cdot\left\{d\left(x_{n-1}, T x_{n}\right)-\operatorname{dist}(A, B)\right\}\right. \\
& \cdot\left\{d\left(x_{n-1}, T x_{n-1}\right)-\operatorname{dist}(A, B)\right\} \\
& \left.\cdot\left\{d\left(x_{n}, T x_{n}\right)-\operatorname{dist}(A, B)\right\}\right) \\
\times & \left(1+d\left(x_{n-1}, x_{n}\right)\right)^{-1}+d\left(x_{n-1}, x_{n}\right) ;
\end{aligned}
$$

that is,

$$
M\left(x_{n-1}, x_{n}\right)=d\left(x_{n-1}, x_{n}\right)
$$

So, we have

$$
d\left(x_{n}, x_{n+1}\right) \precsim k d\left(x_{n-1}, x_{n}\right) .
$$

Then it follows that

$$
\begin{aligned}
d\left(x_{n}, x_{n+1}\right) & \lesssim k d\left(x_{n-1}, x_{n}\right) \precsim k^{2} d\left(x_{n-2}, x_{n-1}\right) \\
& \vdots \cdots \precsim k^{n} d\left(x_{0}, x_{1}\right) .
\end{aligned}
$$

For any $m>n$,

$$
\begin{aligned}
d\left(x_{m}, x_{n}\right) \lesssim & d\left(x_{n}, x_{n+1}\right)+d\left(x_{n+1}, x_{n+2}\right) \\
& +\cdots+d\left(x_{m-1}, x_{m}\right) \\
\precsim & {\left[k^{n}+k^{n+1}+k^{n+2}+\cdots+k^{m-1}\right] d\left(x_{0}, x_{1}\right) } \\
\lesssim & \frac{k^{n}}{1-k} d\left(x_{0}, x_{1}\right) \longrightarrow 0 \quad \text { as } m, n \longrightarrow \infty
\end{aligned}
$$

which implies that $\left\{x_{n}\right\}$ is a Cauchy sequence. From the completeness of $X$, there exists $z \in X$ such that

$$
x_{n} \longrightarrow z \text { as } n \longrightarrow \infty \text {. }
$$

Since $A$ is closed and $\left\{x_{n}\right\}$ is a sequence in $A$ converging to $z$, we have $z \in A$.

By the continuity of $T$, we have

$$
T x_{n} \longrightarrow T z \quad \text { as } n \longrightarrow \infty \text {. }
$$

Then,

$$
d\left(x_{n+1}, T x_{n}\right) \longrightarrow d(z, T z) \quad \text { as } n \rightarrow \infty \text {. }
$$

But according to (14), the sequence $\left\{d\left(x_{n+1}, T x_{n}\right)\right\}$ is a constant sequence with the constant value $\operatorname{dist}(A, B)$. Therefore, $d(z, T z)=\operatorname{dist}(A, B)$; that is, $z \in A$ is a best proximity point of $T$.

Finally, we will prove that such a point is unique.

Suppose that $z^{*} \in A$ is another best proximity point of $T$; that is, $d\left(z^{*}, T z^{*}\right)=\operatorname{dist}(A, B)$. Now, $d(z, T z)=\operatorname{dist}(A, B)$ and $d\left(z^{*}, T z^{*}\right)=\operatorname{dist}(A, B)$ imply that $z, z^{*} \in A_{0}$ and $T z, T z^{*} \in B_{0}$. Since the pair $(A, B)$ satisfies the weak $P$ property, we necessarily have

$$
d\left(z, z^{*}\right) \precsim d\left(T z, T z^{*}\right) .
$$

Now,

$$
d\left(z, z^{*}\right) \lesssim d\left(T z, T z^{*}\right) \lesssim k M\left(z, z^{*}\right)
$$

where

$$
\begin{aligned}
M\left(z, z^{*}\right)=( & \left\{d\left(z^{*}, T z\right)-\operatorname{dist}(A, B)\right\} \\
& \cdot\left\{d\left(z, T z^{*}\right)-\operatorname{dist}(A, B)\right\} \\
& \cdot\{d(z, T z)-\operatorname{dist}(A, B)\} \\
& \left.\cdot\left\{d\left(z^{*}, T z^{*}\right)-\operatorname{dist}(A, B)\right\}\right) \\
& \times\left(1+d\left(z, z^{*}\right)\right)^{-1}+d\left(z, z^{*}\right)=d\left(z, z^{*}\right) .
\end{aligned}
$$

So, we have

$$
d\left(z, z^{*}\right) \lesssim k d\left(z, z^{*}\right),
$$

which is a contradiction unless $d\left(z, z^{*}\right)=0$; that is, $z=z^{*}$. Hence the best proximity point of $T$ is unique.

Corollary 17. Let $(X, d)$ be a complete complex valued metric space. Let $T: X \rightarrow X$ be a mapping such that, for all $x, y \in X$,

$$
d(T x, T y) \lesssim k M(x, y),
$$

where

$$
\begin{aligned}
M(x, y)= & \frac{d(y, T x) \cdot d(x, T y) \cdot d(x, T x) \cdot d(y, T y)}{1+d(x, y)} \\
& +d(x, y), \quad 0<k<1 .
\end{aligned}
$$

Then $T$ has a unique fixed point in $X$. 
Corollary 18. Let $(X, d)$ be a complete complex valued metric space. Let $T: X \rightarrow X$ be a mapping such that, for all $x, y \in X$,

$$
d(T x, T y) \lesssim k d(x, y), \quad \text { where } 0<k<1 .
$$

Then $T$ has a unique fixed point in $X$.

Example 19. Consider $X=C$. Let $d: X \times X \rightarrow \mathscr{C}$ be given as

$$
\begin{aligned}
& \qquad d\left(z_{1}, z_{2}\right)=\left|x_{1}-x_{2}\right|+i\left|y_{1}-y_{2}\right|, \\
& \text { where } z_{1}=x_{1}+i y_{1}, \quad z_{2}=x_{2}+i y_{2} .
\end{aligned}
$$

Then $(X, d)$ is a complex valued metric space with the required properties of Theorem 16.

Let

$$
\begin{aligned}
& A=\{z \in C: \operatorname{Re}(z)=0,0 \leq \operatorname{Im}(z) \leq 1\}, \\
& B=\{z \in C: \operatorname{Re}(z)=1,0 \leq \operatorname{Im}(z) \leq 1\} .
\end{aligned}
$$

Then $(A, B)$ is a pair of nonempty closed and bounded subsets of $X$ such that

$$
\operatorname{dist}(A, B)=1, \quad A_{0}=A, \quad B_{0}=B .
$$

It is verified that the pair $(A, B)$ satisfies the weak $P$-property (precisely, $P$-property).

Let $T: A \rightarrow B$ be defined as follows:

$$
T z=1+i \frac{y}{2}, \quad \text { for } z=x+i y \in A
$$

Then $T$ satisfies the properties mentioned in Theorem 16 .

It can be verified that inequality (12) is satisfied. Hence the conditions of Theorem 16 are satisfied and it is seen that 0 is the unique best proximity point of $T$.

Example 20. We take the complex valued metric space $(X, d)$ considered in Example 19. Let

$$
\begin{aligned}
A= & \{z \in C: \operatorname{Re}(z)=-1,0 \leq \operatorname{Im}(z) \leq 1\} \\
& \cup\{z \in C: \operatorname{Re}(z)=1,0 \leq \operatorname{Im}(z) \leq 1\}, \\
B= & \{z \in C: \operatorname{Re}(z)=-2,0 \leq \operatorname{Im}(z) \leq 1\} \\
& \cup\{z \in C: \operatorname{Re}(z)=2,0 \leq \operatorname{Im}(z) \leq 1\} .
\end{aligned}
$$

Then $(A, B)$ is a pair of nonempty closed and bounded subsets of $X$ such that

$$
\operatorname{dist}(A, B)=1, \quad A_{0}=A, \quad B_{0}=B .
$$

It is verified that the pair $(A, B)$ satisfies the weak $P$-property.

Let $T: A \rightarrow B$ be defined as follows:

$$
T z=2|x|+i \frac{1}{2} y, \quad \text { for } z=x+i y \in A .
$$

Then $T$ satisfies the properties mentioned in Theorem 16.

It can be verified that inequality (12) is satisfied. Hence the conditions of Theorem 16 are satisfied and it is seen that 1 is the unique best proximity point of $T$.
Note 3. As explained in Example 14, the pair $(A, B)$ in the above example satisfies the weak $P$-property but does not satisfy the $P$-property.

\section{Conflict of Interests}

The authors declare that there is no conflict of interests regarding the publication of this paper.

\section{References}

[1] B. F. Schutz, Geometrical Methods of Mathematical Physics, Cambridge University Press, 1980.

[2] M. P. Hobson, G. P. Efstathiou, and A. N. Lasenby, General Reltivity, Cambridge University Press, New York, NY, USA, 2006.

[3] K. Fan, "Extensions of two fixed point theorems of F. E. Browder," Mathematische Zeitschrift, vol. 112, pp. 234-240, 1969.

[4] A. A. Eldred and P. Veeramani, "Existence and convergence of best proximity points," Journal of Mathematical Analysis and Applications, vol. 323, no. 2, pp. 1001-1006, 2006.

[5] M. A. Al-Thagafi and N. Shahzad, "Convergence and existence results for best proximity points," Nonlinear Analysis: Theory, Methods \& Applications, vol. 70, no. 10, pp. 3665-3671, 2009.

[6] J. Caballero, J. Harjani, and K. Sadarangani, "A best proximity point theorem for Geraghty-contractions," Fixed Point Theory and Applications, vol. 2012, article 231, 2012.

[7] B. S. Choudhury, P. Maity, and P. Konar, "A global optimality result using nonself mappings," Opsearch, vol. 51, no. 2, pp. 312320, 2014.

[8] C. Di Bari, T. Suzuki, and C. Vetro, "Best proximity points for cyclic Meir-Keeler contractions," Nonlinear Analysis: Theory, Methods \& Applications, vol. 69, no. 11, pp. 3790-3794, 2008.

[9] W. A. Kirk, S. Reich, and P. Veeramani, "Proximinal retracts and best proximity pair theorems," Numerical Functional Analysis and Optimization, vol. 24, no. 7-8, pp. 851-862, 2003.

[10] W. A. Kirk, P. S. Srinivasan, and P. Veeramani, "Fixed points for mappings satisfying cyclical contractive conditions," Fixed Point Theory, vol. 4, no. 1, pp. 79-89, 2003.

[11] V. Pragadeeswarar and M. Marudai, "Best proximity points: approximation and optimization in partially ordered metric spaces," Optimization Letters, vol. 7, no. 8, pp. 1883-1892, 2013.

[12] S. Sadiq Basha, "Best proximity points: optimal solutions," Journal of Optimization Theory and Applications, vol. 151, no. 1, pp. 210-216, 2011.

[13] V. S. Raj, "A best proximity point theorem for weakly contractive non-self-mappings," Nonlinear Analysis: Theory, Methods of Applications, vol. 74, no. 14, pp. 4804-4808, 2011.

[14] J. Zhang, Y. Su, and Q. Cheng, "A note on a best proximity point theorem for Geraghty-contractions," Fixed Point Theory and Applications, vol. 2013, article 99, 2013.

[15] A. Azam, B. Fisher, and M. Khan, "Common fixed point theorems in complex valued metric spaces," Numerical Functional Analysis and Optimization, vol. 32, no. 3, pp. 243-253, 2011.

[16] S. Bhatt, S. Chaukiyal, and R. C. Dimri, "A common fixed point theorem for weakly compatible maps in complex valued metric spaces," International Journal of Mathematical Sciences of Applications, vol. 1, no. 3, pp. 1385-1389, 2011. 
[17] W. Sintunavarat and P. Kumam, "Generalized common fixed point theorems in complex valued metric spaces and applications," Journal of Inequalities and Applications, vol. 2012, article 84, 12 pages, 2012.

[18] K. Sitthikul and S. Saejung, "Some fixed point theorems in complex valued metric spaces," Fixed Point Theory and Applications, vol. 2012, article 189, 2012.

[19] S. Gähler, "Über die UNIformisierbarkeit 2-metrischer Räume," Mathematische Nachrichten, vol. 28, pp. 235-244, 1964.

[20] B. Schweizer and A. Sklar, "Statistical metric spaces," Pacific Journal of Mathematics, vol. 10, pp. 313-334, 1960.

[21] B. Schweizer and A. Sklar, Probabilistic Metric Spaces, Dover, Incorporated, New York, NY, USA, 2011.

[22] A. George and P. Veeramani, "On some results in fuzzy metric spaces," Fuzzy Sets and Systems, vol. 64, no. 3, pp. 395-399, 1994.

[23] O. Kaleva and S. Seikkala, "On fuzzy metric spaces," Fuzzy Sets and Systems, vol. 12, no. 3, pp. 215-229, 1984.

[24] Z. Mustafa and B. Sims, "Some remarks concerning D-metric spaces," in Proceedings of the International Conference on Fixed Point Theory Applications, pp. 189-198, Valencia, Spain, 2003. 


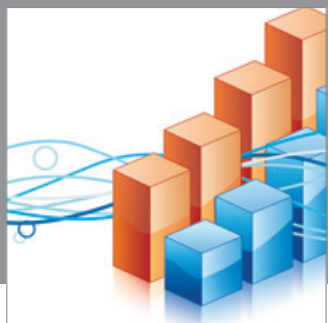

Advances in

Operations Research

mansans

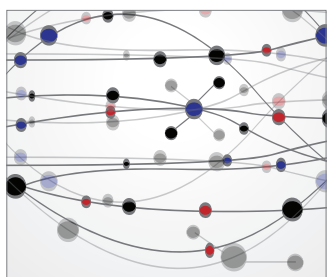

The Scientific World Journal
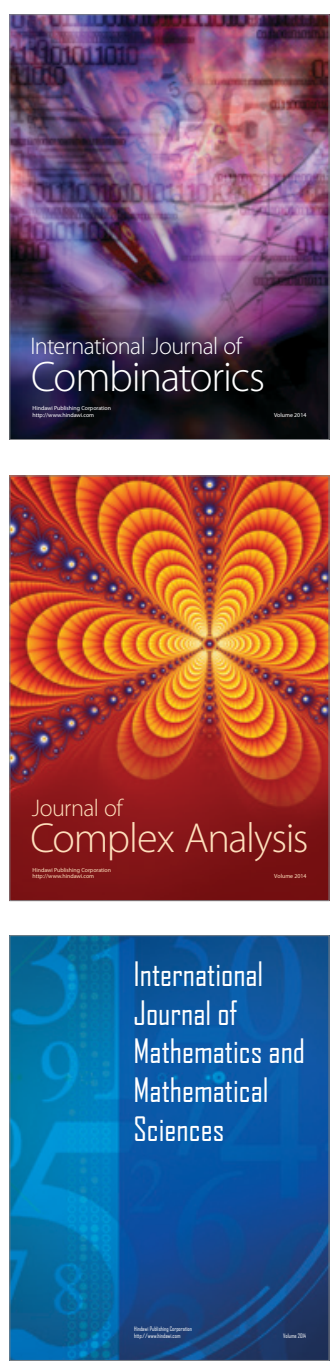
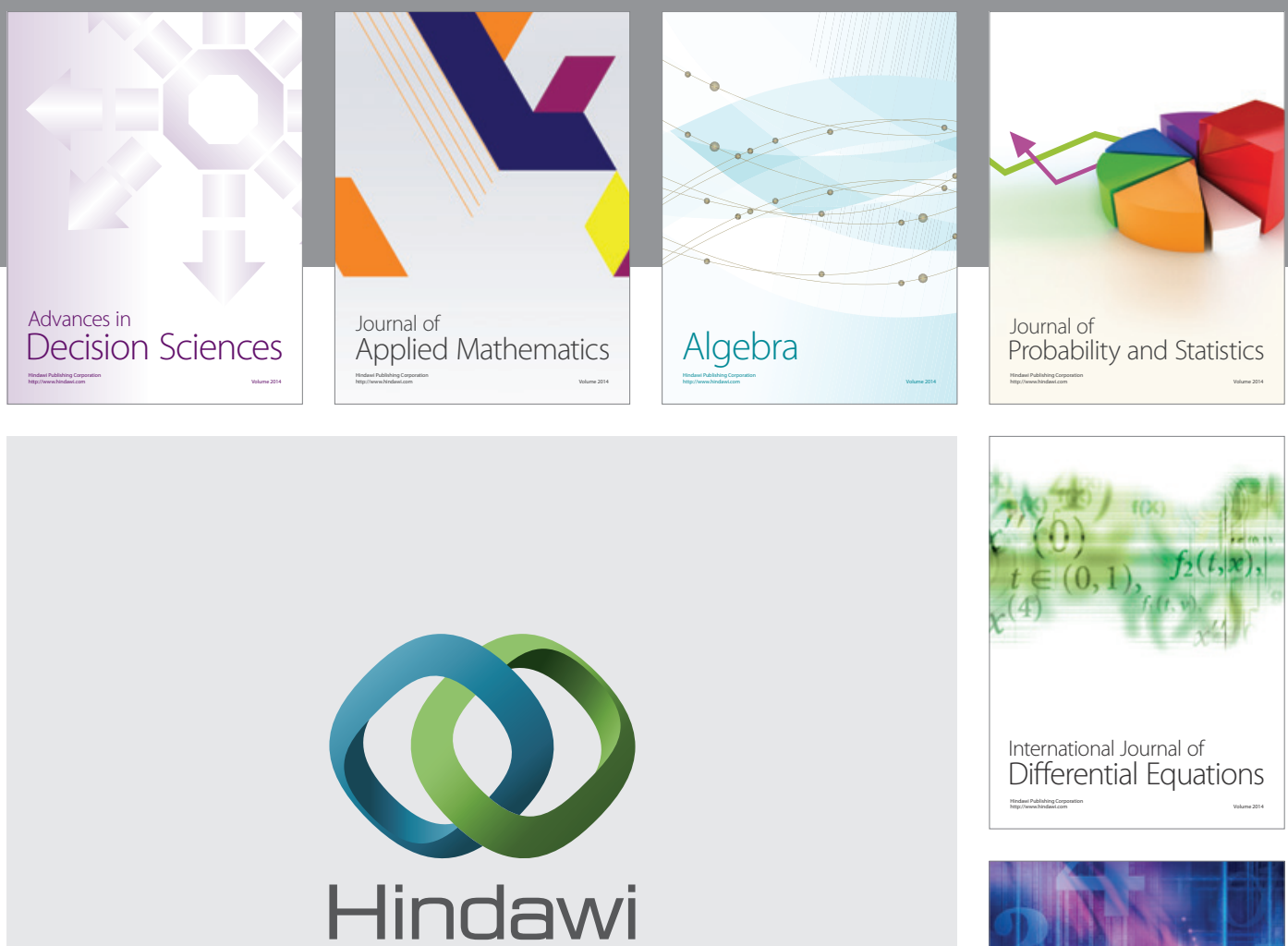

Submit your manuscripts at http://www.hindawi.com
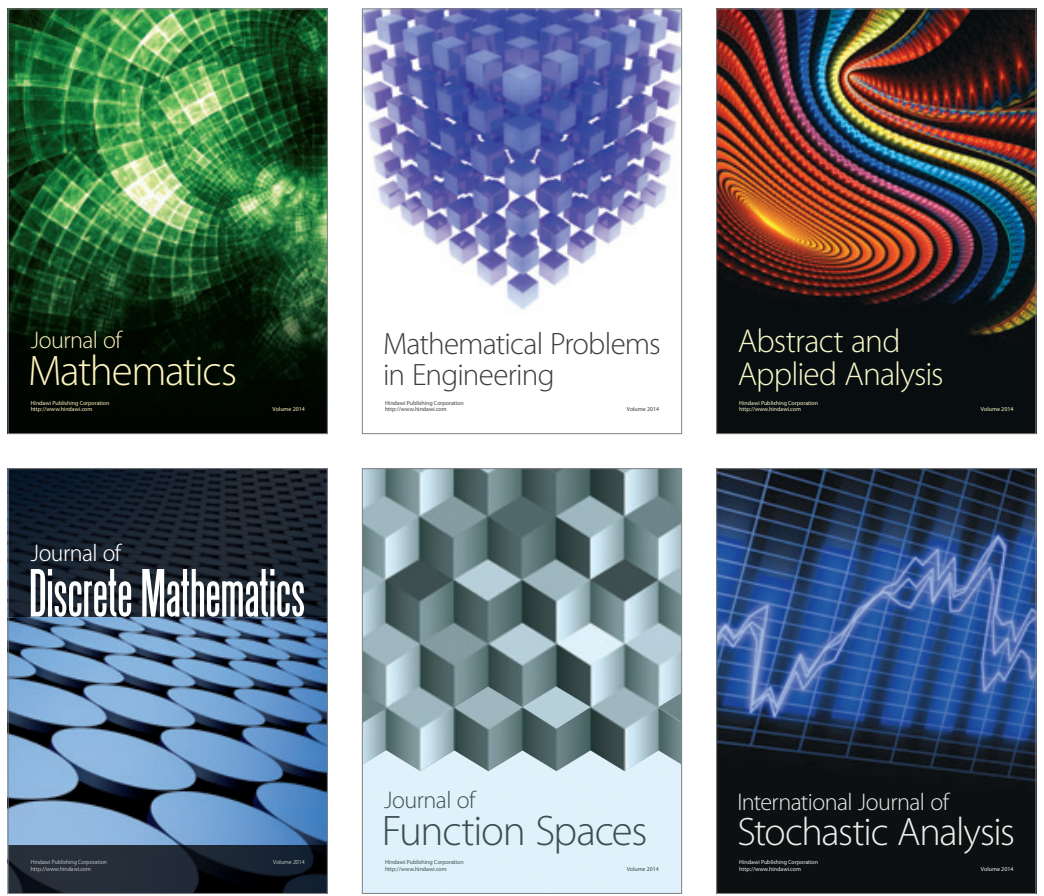

Journal of

Function Spaces

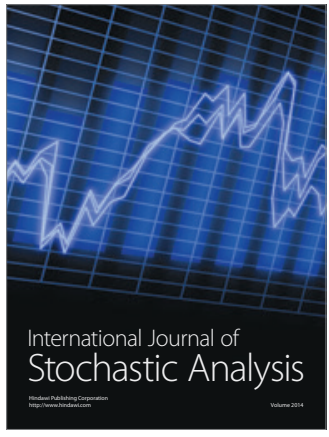

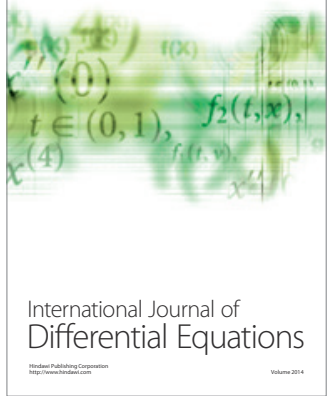
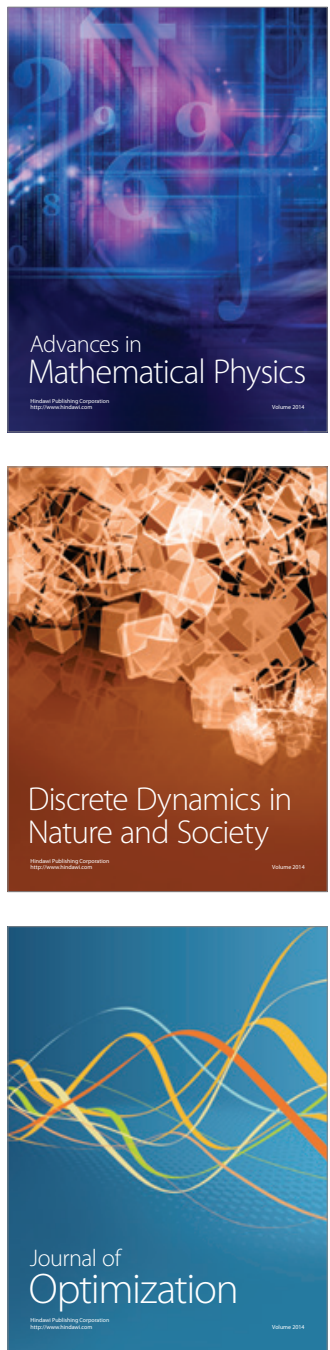